\title{
As 40 horas de Angicos, a UFRN, a UNE e Paulo Freire (Rio Grande do Norte, 1963)
}

The 40 hours of Angicos, the UFRN, the UNE and Paulo Freire (Rio Grande do Norte, 1963)

Marcos José de Castro Guerra Coordenador de um Círculo de Cultura, na cadeia pública de Angicos

Poucos sabem que ahistórica "40 horas de Angicos" teve como núcleo principal duas dezenas de estudantes universitários de nossa Universidade Federal do Rio Grande do Norte (UFRN), além de três estudantes secundaristas. Os coordenadores dos Círculos de Cultura na cidade de Angicos (Rio Grande do Norte) partiram das Faculdades de Direito (José Ribamar de Aguiar, Marcos José de Castro Guerra, Pedro Neves Cavalcanti e Valquíria Felix), Farmácia (Dilma Ferreira Lima), Jornalismo(Carlos Augusto Lyra Martins), Filosofia e Pedagogia (Giselda Gomes Salles, Lenira Leite, Marlene Vasconcelos, Rosali Liberato e Valdinece Correia Lima),Medicina (Evanuel Elpídio da Silva, 234 Geniberto Paiva Campos, Maria Laly Carneiro), Odontologia (Margarida Magalhães) e Serviço Social (Maria do Carmo Correia Lima). Dois estudantes secundaristas oriundos do Atheneu Norte-Riograndense de Natal (Edilson Dias de Araújo e Talvane Guedes) e uma terceira de Recife (Madalena Freire).

À época, fomos chamados pela União Nacional dos Estudantes (UNE), através de sua União Estadual (UEE), com atuação marcante dentro das Universidades Brasileiras. Após um trabalho de reflexão sobre a Reforma Universitária, tivemos sucesso no Rio Grande do Norte quanto a uma de suas bandeiras, resultado da chamada "Greve de 1/3" que conquistou participação estudantil no Conselho gestor da Universidade. Tínhamos várias ações inspiradas na UNE-VOLANTE, nascidas no centro popular de cultura (CPC) da UNE (GARCIA, 2014), e fruto do real protagonismo da juventude naquele momento político brasileiro.

Em todo o Brasil, a UNE mobilizou os universitários para restituir à população parte do que recebíamos. Éramos apenas 100.000 estudantes nas universidades públicas brasileiras, um por cento (1\%) da população. Assim, nasceram múltiplas ações, nas próprias faculdades ou nos bairros, através das quais estudantes apoiavam atividades comunitárias ou atendiam, entre outras, 
demandas localizadas de assessoria jurídica, assistência social, atendimento em cuidados básicos de saúde, apoio em engenharia e saneamento. Foram ações precursoras do que seria mais tarde o Centro Rural Universitário de Treinamento e Ação Comunitária (Crutac)da UFRN (1966) e o Projeto Rondon (1967).

Assim,começou, naturalmente, a participação dos universitários, desde o início das três principais atividades de educação popular no Rio Grande do Norte: a pioneira educação radiofônica do Movimento de Educação de Base (MEB, 1958), a alfabetização nos acampamentos implantados pela Prefeitura Municipal de Natal em sua Campanha "De Pé no Chão Também se Aprende a Ler" (1961) e nossa atuação no Sistema Paulo Freire, da Secretaria Estadual da Educação do Rio Grande do Norte (1963).

\section{As 40 horas, e o inexplicável esquecimento}

Sobre as teorias de Paulo Freire, existem centenas de livros, teses e monografias. Muito pouco, sobre as práticas. Menos ainda, resultante de pesquisa concreta com ex-alunos, que se alfabetizaram em Angicos, Natal, Mossoró, e nas cidades satélites em torno de Brasília. Aprofundam-se as teorias, repetidas e interpretadas em detalhes. Descrevem-se as experiências, sem renová-las. É como se bastasse retirá-las de um congelador, descrevê-las, com cuidado para que não retomem vida, não venham contaminar o que poderia ser feito no século XXI.

Confesso meu espanto diante de tal lacuna, que não é responsabilidade somente das faculdades de educação. Poderiam ter despertado o interesse de estudiosos da história, da sociologia, da política, dos direitos, do jornalismo, da comunicação, dentre tantos outros. A implantação do Sistema Paulo Freire, duramente reprimida pela Ditadura, demonstra tudo o que temiam os militares e seus aliados: inovação com resultados positivos e duráveis, solução rápida e barata para que milhares de brasileiros se alfabetizassem em pouco tempo, sem risco de esquecer o que aprenderam.

É como se permanecesse o "diktat" da ditadura que atemorizou muitos, professores e alunos, e - salvo honrosas exceções - perdura desde a redemocratização (1986) e da nova Constituição Federal que oferece 
amplas garantias desde 1988. A interdição atingiu também os sucessivos governos que não souberam honrar o legado de Paulo Freire. É grave constatarmos que optaram pela omissão ou por descaminhos em relação ao tema, os Presidentes da República e seus Ministros da Educação, desde 1995- com exceção de uma determinação inicial demonstrada pelo então Ministro Cristovam Buarque, que não teve tempo para concretizar suas intenções. Não souberam compatibilizar seu inegável compromisso político e discurso progressista com ações efetivas que garantam a universalização do direito à educação. Quando se conhece como agem os Governos, o correto seria utilizar o verbo adequado, trocar "souberam" por "quiseram", o que torna mais inexplicável a situação. E quiseram privilegiar outras frentes, igualmente legítimas e importantes, como o ensino técnico e o ensino universitário, sem cuidar da base da pirâmide nem do sagrado direito à educação, tendo a alfabetização como porta de entrada para o exercício da cidadania e do mínimo de dignidade.

\section{Porque Paulo Freire, e porque Angicos?}

No Rio Grande do Norte, tínhamos duas inovações qualitativas em matéria de educação popular, já mencionadas - o MEB implantado pelo Movimento de Natal através da Radio Rural, e a Campanha "De Pé no Chão Também se Aprende a Ler", da Prefeitura de Natal. Em ambas, o aprofundamento teórico e as questões operacionais foram desenvolvidos com participação efetiva de estudantes da UFRN, motivados pela UEE-UNE. Naturalmente, fomos convidados pelo novo Governo do Estado para contribuir na definição e implantação de um ousado programa de alfabetização através da Secretaria da Educação. Ao assumir,em 1961, o Governador Aluízio Alves trazia compromissos com uma renovação da máquina administrativa, e uma nova definição de prioridades. Dentre estas, energia, estradas e telefonia. E um desenvolvimento planejado, nos moldes do que se preconizava na época, inspirado pela Comissão Econômica da Organização das Nações Unidas para a América Latina (CEPAL) que dava prioridade à Educação como fator de desenvolvimento. O Governador procurou apoio dentre os estudantes universitários, para integrar o corpo inicial do Conselho Estadual do Desenvolvimento (CED), das empresas telefônica e distribuidora de energia do Estado, respectivamente da Companhia Telefônica do Rio Grande do Norte (Telern) e da Companhia Elétrica do Estado do Rio Grande do Norte (Cosern), dentre outras iniciativas inovadoras. 
Surge então uma coincidência de objetivos, entre o novo governante e as prioridades dos estudantes. Quebrando paradigmas, o Governador confiou a Secretaria da Educação ao jornalista Calazans Fernandes, nascido na Tromba do Elefante, com larga experiência profissional desenvolvida no Rio de Janeiro. Idealista e empreendedor com ampla visão, ele propôs que o Estado implantasse métodos similares enquanto inovação, embora com maior ambição quanto aos resultados. Para tal, abriu diálogo com os estudantes, a partir da União Estadual dos Estudantes.

Dentre outras ações inovadoras e com resultados positivos, conhecíamos o que faziam os pernambucanos no Movimento de Cultura Popular (MCP), criado em 1960 pelo Prefeito Miguel Arraes. O MCP trabalhava com Cartilha, mas Paulo Freire, um dos educadores do movimento, havia realizado duas micro experiências utilizando um método inovador, sem cartilha, e com resultados muito rápidos. Enquanto chegávamos a esta conclusão, coincidentemente o Calazans interessou-se pela mesma experiência, e procurou conversar com Paulo Freire, sendo intermediado por Odilon Ribeiro Coutinho, amigo de ambos.

Angicos foi selecionado pelo Governador, por várias razões. É sua terra de origem, sua base política. Na época, os analfabetos não tinham direito a votar. Ele sabia que seus aliados iriam cobrar mais adiante ter formado novos eleitores, desequilibrando colégios cativos, os chamados "currais eleitorais" e seus "votos de cabresto". Em Angicos, havia uns 800 (oitocentos) eleitores inscritos, e, de repente, 300 (trezentos) novos eleitores representavam uma ameaça potencial, e novas exigências para qualquer dirigente político.

Além do mais, todo político sente-se bem quando pode dar prioridade aos seus, à sua terra. E podia contar com o apoio necessário de vários atores, como o Prefeito, o Vigário e membros da comunidade.

\section{Cooperação Internacional e apoio do MEC}

Com um plano de governo ousado, querendo fazer "em apenas três anos o que não se fez em três séculos", o Governador Aluízio Alves procurou financiamentos federais e de outros países, num momento favorável. Rapidamente, tentou beneficiar-se de recursos do programa lançado, em 1961 , pelo Presidente Kennedy, a "Aliança para o Progresso". Após tentar 
financiamento direto através de doação, teve que apelar para o Governo Federal, único habilitado a formalizar parcerias com Governos de outros países. Contou com o apoio do Presidente João Goulart, e mais diretamente de seus Ministros da Educação, Darcy Ribeiro e do Planejamento, Celso Furtado - que também dirigia a Superintendência do Desenvolvimento do Nordeste (Sudene). Assim, foi negociado um programa para o Rio Grande do Norte, com vários objetivos, entre os quais importantes somas para a educação.

Em plena Guerra Fria, militantes e educadores de esquerda em toda a América Latina não aceitavam qualquer forma de cooperação com o Programa norte americano. (KIRKENDALL, 2010). Por isso, encontramos oposição ferrenha nos quadros dirigentes da UNE e da UEE, e dos líderes políticos Djalma Maranhão e Miguel Arraes. Entendiam que aceitar uma aliança com os norte-americanos iria reforçar o Governo Aluízio Alves e contribuir para o pré-lançamento de um eventual candidato forte nas futuras eleições, nas quais, inevitavelmente ele estaria associado à oposição dos candidatos municipais e ao Governo Estadual, do bloco liderado pelo Presidente João Goulart e seus aliados políticos. Evidenciado o Acordo internacional com a Aliança para o Progresso, entendiam que deveríamos sair denunciando os reais objetivos dos norte-americanos. O tema foi objeto de diálogo franco, respeitoso e demorado, e nos levou a um rompimento quanto a essa decisão específica. Paulo Freire exigiu a intermediação da Sudene para receber e gerenciar os recursos financeiros e o acompanhamento dos trabalhos, um Convênio entre o Governo do Rio Grande do Norte e o Serviço de Extensão Cultural da Universidade de Recife, do qual era Diretor, além de plena autonomia política e operacional, ficando a Direção do Setor de Educação de Jovens e Adultos com a liderança estudantil em quem confiava.Com as voltas que o mundo dá, cursando o segundo ano de Direito na Faculdade da Ribeira, e presidindo a UEE, recebi convite para tal tarefa, apresentado por Paulo Freire como convocação irrecusável.

Estes e outros assuntos relacionados com a montagem institucional foram desenvolvidos em recente artigo publicado na Revista de Informação do Semiárido (GUERRA, 2013), por ocasião das solenidades que celebraram os 50 anos das 40 horas de Angicos. De abril a dezembro de 2013, múltiplos eventos celebraram o aniversário, em programa organizado pelo Ministerio da Educação e Cultura (MEC), as Secretarias da Educação do Estado do Rio Grande do Norte e do Município de Angicos, a Universidade Federal do Semiárido, e muitas outras entidades ${ }^{1}$. 


\section{Inovação, resultados duráveis, custo, rapidez}

Atraíram o Secretário Calazans Fernandes e o próprio Governador do Estado alguns aspectos metodológicos preconizados por Paulo Freire. Não existia Cartilha previamente impressa pelo Programa. Ao invés de palavras e temas escolhidos por profissionais da educação, cada aluno criava a sua, com suas palavras e frases. A proposta era completar um ciclo de alfabetização que permitisse em, no máximo, 40 horas o pleno domínio da leitura, e a capacidade de escrever palavras, mensagens, recados e cartas simples. Essa opção tinha consequências logísticas que não podiam deixar de atrair quem estava com um programa de governo denso, apressado e ambicioso. Tinha logística mais simples e custos bem menores.

Os resultados duráveis pareciam assegurados pelas duas experiências pioneiras feitas em Recife por Paulo Freire, juntamente com o então estudante de Medicina Carlos Augusto Nicéas de Almeida. São consequência direta de um aspecto fundamental da aprendizagem, que se faz a partir das palavras e situações geradoras dos próprios alunos. Trabalhando com jovens e adultos, conscientes de que não estávamos com "analfabetos orais", era a própria vida e o quotidiano dos alfabetizandos que determinavam as palavras geradoras e os conteúdos dos programas de alfabetização. Assim, a ferramenta não iria ser encostada como acontece com a Cartilha, seria utilizada a cada momento, ao longo do dia, tornando-se multifacetada.

Faltava garantir a motivação dos alunos. Um levantamento detathado identificou quantos analfabetos existiam em cada casa de Angicos, e uma campanha foi elaborada para motivá-los, incluindo visita domiciliar pelos futuros coordenadores dos Círculos de Cultura. Círculos que substituíram as tradicionais salas de aula, onde um professor sabe e os outros aprendem de forma, muitas vezes, passiva.

Mas o principal da motivação viria dos próprios alunos. Uns porque queriam escrever a seus familiares que partiram nas migrações determinadas pelas secas, ou ler suas cartas, sem intermediários. Outros para ler a Bíblia ou jornais, para assinar seu próprio nome, para votar, e tantos outros motivos pessoais altamente válidos.

Finalmente, redescobririam, ao longo das duas primeiras noites um inesperado fator de motivação. Ao dialogarem longamente sobre as imagens projetadas a partir de slides coloridos, puderam apreender o Conceito 
Antropológicode Cultura. Identificando "objetos da natureza" e "objetos da cultura", perceberam como poderiam sair da cultura do silêncio na qual a maioria estava imersa, e descobrir quanto os homens, em seu quotidiano, contribuem para modificar o mundo, acrescentar ao mundo coisas que não encontraram feitas; ação consciente própria da natureza humana - que nos diferencia dos animais. (LYRA, 1996). Nos últimos slides da primeira noite, todos discutem como mestres o que diferencia a caça com arco e flecha dos primeiros índios, a do caçador com espingarda, daquela ainda instintiva do gato e do rato. $\bigcirc$ entusiasmo é tão grande que alguns chegam a afirmar que "não aprenderam nada de novo, apenas recordaram o que sabiam, embora muitos tivessem esquecido".

\section{A alfabetização}

Começamos em 18 de janeiro de 1963, e a aula de encerramento foi ministrada pelo Presidente da República, João Goulart, em 2 de abril do mesmo ano.

Existem relatos sobre a aprendizagem do ler e escrever; a partir
240 das palavras geradoras, dominam progressivamente todos os fonemas da nossa língua portuguesa. (FERNADES; TERRA, 1994). Todas elas, repetimos, oriundas de seu "universo vocabular", identificado através de uma pesquisa efetuada pelos futuros monitores das 40 horas de Angicos. A alfabetização ocorre, naturalmente, com base nos dos debates sobre as "situações geradoras" nos quais se posicionam de maneira progressivamente crítica, quando dialogam sobre os temas suscitados pelas "palavras geradoras", a partir de slides contendo imagens e também a palavra escrita. As palavras geradoras utilizadas em Angicos fora: Belota, Sapato, Voto Povo, Salina, Feira Milho, Goleiro, Cozinha, Chibanca, XiqueXique, Tijela Jarra, Fogão, Expresso, Bilro, Almofada.

Para preparar os futuros "alfabetizadores", fizemos um Seminário com Paulo Freire e sua equipe da Universidade do Recife, em dezembro de 1962. Dentre outras coisas, aprendemos a força do diálogo socrático, e aprendemos que "ninguém educa ninguém, ninguém se educa sozinho, os homens se educam entre si, mediatizados pelo mundo." Durante a experiência inicial, tivemos a assessoria de Paulo e sua equipe, quando visitaram os trabalhos e nas reuniões matutinas que chamávamos de Seminários. 


\section{A repressão da Guerra Fria}

Nos Estados Unidos, os aliados do Departamento de Defesa haviam derrotado os aliados do Presidente John Kennedy, que integravam o Departamento de Estado. Aqui, sob as ordens dos mesmos aliados do Pentágono, para quem a indústria da guerra inventa todas as desculpas, agentes uniformizados do Estado cumpriram sua parte. Destruíram materiais e arquivos, atemorizaram ex-alunos e ex-professores. Alguns chegaram a ser presos, torturados, ou exilados, enquanto os algozes conseguiram seu objetivo espúrio: em números absolutos, temos hoje no Brasil mais analfabetos que no início dos anos 1960. O surpreendente é que continuam ganhando, na medida em que, como foi dito acima, nada foi feito para retomar uma alfabetização simples, barata e rápida, a única que pode, em pouquíssimo tempo, universalizar o acesso de todos a essa simples porta de entrada que thes é negada.

Paulo Freire havia sido convidado para abrir uma Campanha Nacional no MEC, iniciando por Sergipe e pelo Estado do Rio. No Rio Grande do Norte, teríamos 100.000 alfabetizados a mais, e, no Brasil, a meta era que 6 Milhões de brasileiros se integrassem com maior dignidade na vida nacional. Documentário recente feito pela mesma Universidade Federal Rural do Semi-Árido (UFERSA) recolheu testemunho direto de ex-alunos das "40 horas de Angicos", e fica patente o orgulho que têm porque "todos os filhos foram à Escola", e alguns dos netos estão na Universidade. Ganharam os que preferiram manter o status quo.

Como honrar o legado de Paulo Freire, respeitando efetivamente o que tem sido anunciado ao longo das últimas celebrações dos 50 anos das 40 horas de Angicos?

No início, os estudantes da UFRN tomaram para essa tarefa, mobilizados pela UNE e pela UEE. Estaríamos num momento propício para que, ao menos, criem condições de diálogo com diversos parceiros sobre esta questão? Resta-nos esta esperança, quando vemos redobrado o interesse das Universidades enquanto centros de produção de conhecimentos, de pesquisa, e de formação, infelizmente reservado ainda a poucos. 


\section{Nota}

1 Ver em: http://angicos50anos.paulofreire.org

\section{Referências}

KIRKENDALL, Andrew J. Paulo Freire and the cold war politics of literacy. Chapel Hill: Universityof North Carolina Press, 2010.

GARCIA, Milandre. A questão da cultura popular: as políticas culturais do centro popular de cultura (CPC) da União Nacional dos Estudantes (UNE). Revista Brasileira de História, São Paulo, v. 24, n. 47, p. 127-62, jul. 2004.

GUERRA, Marcos José de Castro As 40 horas de angicos: vítimas da guerra fria? Revista de Informação do Semiárido, Angicos, v. 1, n. 1, p. 22-46, jan./jun. 20 13 . (Edição Especial).

Lyra, Carlos. As quarenta horas de Angicos: uma experiência pioneira de educação. São Paulo: Cortez Pereira, 1996.

TERRA, Antonia Fernandes Calazans. 40 horas de esperança. $\bigcirc$ método Paulo Freire: política e pedagogia na experiência de Angicos. São Paulo: Ática, 1994.

Prof. Marcos José de Castro Guerra Universidade Federal do Rio Grande do Norte Programa de Pós-Graduação em Direito Internacional Prof. de Direito dos Estrangeiros

Diretor do Setor de Educação de Jovens e Adultos (1962-1964) e Coordenador de um Círculo de Cultura, na cadeia pública de Angicos Membro da Comissão Brasileira de Justiça e Paz

Secretário da Educação do Rio Grande do Norte (1991-1994), Diretor Regional do SENAI (1 995-2003), e Consultor das Nações Unidas (1980-1990)

E-mail | miguerra@uol.com.br

Recebido 09 dez. 2013

Aceito 16 dez. 2013 